América sin Nombre, n. ${ }^{\circ} 24$ (2019): 63-71

DOI 10.14198/AMESN.2019.24-1.05

ISSN: 1577.3442 / eISSN: 1989-9831

Fecha de recepción: 10/02/2019

Fecha de aceptación: 03/07/2019
Modo de citación de este artículo:

Bogoya, Camilo. «La literatura colombiana: ¿̇un problema de fronteras?». La nueva novela latinoamericana sin limites. Lise Segas y Félix Terrones (coordinadores). América sin Nombre, 24 (2019): 63-71, DOI: 10.14198/ AMESN.2019.24-1.05

Link para este artículo: http://dx.doi.org/10.14198/AMESN.2019.24-1.05

\title{
La literatura colombiana: ¿un problema de fronteras?
}

\author{
Colombian literature: a border problem?
}

\author{
Camilo Bogoy** \\ Universidad de Artois (Francia)
}

\section{Resumen}

A partir del modernismo las literaturas latinoamericanas se liberan de un imperativo nacionalista, necesario para construir la idea de nación. En los inicios del siglo XXI, con el derrumbe paulatino de las fronteras, la fragmentación política, la atomización de los géneros, y al mismo tiempo con la tendencia a las narrativas globales y al ensanchamiento de los modos de vida y de producción, paradójicamente el siglo xix retorna: surgen de nuevo dos fuerzas que se convierten en un problema literario. Para los novelistas colombianos, la novela estaría a medio camino entre la vieja necesidad de construir un relato nacional, y la impronta de una estética desnacionalizada y global. ¿Cómo estas fuerzas terminan siendo el eje de una narrativa? Estudiaremos esta pregunta a partir de los ensayos de Pablo Montoya y Juan Gabriel Vásquez, así como de sus novelas Los derrotados y La forma de las ruinas.

Palabras clave: Pablo Montoya, Juan Gabriel Vásquez, literatura colombiana, nacional, globalización

\begin{abstract}
From the modernism, Latin American literatures fly free from a nationalist imperative, until then needed to construct the idea of the nation. At the beginning of the twenty-first century, with the gradual collapse of borders, political fragmentation, atomization of genres, and at the same time with the tendency towards global narratives and the amplification of ways of life and production, paradoxically the nineteenth century returns: two forces re-emerge and become a literary problem. For Colombian novelists, the novel would be halfway between the old necessity to build a national story, and the imprint of a denationalized and global aesthetic. How do these forces end up being the axis of a narrative? We will study this question from the essays of Pablo Montoya and Juan Gabriel Vásquez, as well as their novels Los derrotados and La forma de las ruinas.
\end{abstract}

Keywords: Pablo Montoya, Juan Gabriel Vásquez, colombian literature, national, globalization

\footnotetext{
* Profesor titular de Literatura latinoamericana en la Universidad de Artois. Es autor de una monografía sobre el poeta León de Greiff, y de una tesis doctoral sobre Pascal Quignard. Ha consagrado numerosos artículos a la literatura latinoamericana (Borges, Saer, Vallejo, Vásquez, Montoya, entre otros). Sus investigaciones se centran en la figura del escritor ensayista, así como en la mediación entre la poesía, la novela y el ensayo. Una parte de sus escritos explora la relación entre música y literatura. Igualmente traduce del francés al español a autores contemporáneos (Fanny Taillandier, Hervé Bouchard). En el campo de la ficción ha publicado dos volúmenes de cuentos, El soñador y Ética para infractores.
} 
En una época en que las fronteras se vuelven dudosas, en que los umbrales, lo híbrido, lo global y lo trans son las poéticas dominantes, ¿podemos hablar aún de literatura colombiana? Si desde el siglo XVI, y sobre todo el XIX con los avatares de la Independencia, se ha pensado la literatura como un correlato político, social y cultural del proceso de construcción de la nación, ¿qué relación persiste hoy entre la novela y la necesidad de un relato nacional? ¿Es posible ser una narrador colombiano fuera de los estigmas comerciales y canónicos de la tradición literaria? ¿Qué significa lo nacional para los narradores de hoy? Siguiendo estos interrogantes, el propósito de estas páginas es examinar cómo se problematiza la idea de una literatura vernácula, y por consiguiente la tensión que hay entre lo nacional y lo transnacional. Esta fricción se detallará siguiendo algunos ensayos de Pablo Montoya y Juan Gabriel Vásquez, así como también confrontando de manera breve dos obras mayores de su reciente producción novelística: Los derrotados de Montoya y La forma de las ruinas de Vásquez.

\section{¿Hacia una literatura nacional?}

Hablar de una literatura nacional remite a la relación conflictiva entre literatura y política. Dicho en otros términos, la literatura vino a apoyar la construcción del relato nacional, tan en boga en el siglo XIX y tan necesario para el control político de las élites criollas. La construcción de la naciente República se apoyó en formas culturales subordinadas a un proyecto excluyente de nación. A finales del siglo xx, los politólogos empiezan a trabajar la idea de una «nación impuesta» desde la Constitución de 1886, la cual pretendió abolir, a través de la centralización del poder, las diferencias regionales y la pluralidad étnica (Toro 58-64). A finales del siglo $\mathrm{xx}$, y en parte con la nueva Constitución de 1991, la nación empieza a cambiar su relato. Desde el punto de vista de la literatura como expresión problemática de lo nacional, aparecen nuevas perspectivas que buscan discutir la idea de una supuesta nación literaria y que modifican el discurso hegemónico de la historia anterior.

Si bien desde 1942 con El panorama de la literatura colombiana de Nicolás Bayona Posada, la historiografía empieza a considerar una tradición que precede los textos de la Conquista, hay que esperar a finales de siglo para que por doquier los investigadores insistan en formular una visión incluyente. En las últimas décadas, se multiplican los estudios en que aparecen con vigor las literaturas indígenas, las voces africanas, la literatura femenina, vastos conglomerados de textos que habían apenas rozado la historia oficial y que existían en una temporalidad paralela, fuera del sistema literario, en una periferia que es la imagen crítica del centralismo cultural colombiano.

En otras palabras, la idea de una literatura nacional empieza a ponerse en vilo con el auge dado a las literaturas regionales, marginadas, aparentemente recién descubiertas, literaturas que reivindican a través de los historiadores un lugar en la memoria literaria y que de la mano del discurso académico han ido legitimando una posición. Si bien una perspectiva incluyente cambia el corpus y en ese sentido vuelve plural la realidad, el problema sigue siendo el mismo: ¿cómo definir la literatura colombiana? ¿Cómo definir sus márgenes? ¿Hay una frontera posible o se trata de una pregunta con fines pedagógicos y escolares, se trata de un acuerdo tácito, políticamente correcto?

Una primera respuesta viene de los grupos de investigación que han abordado esta problemática: «la literatura colombiana trasciende el concepto de literatura nacional, si se entiende esta como una especie de literatura ancilar puesta al servicio del proyecto de nación» (Vallejo Murcia, "Colombia. Tradiciones de la palabra» 26). La literatura mantiene una fricción con la política, mas no se subordina a sus necesidades culturales. La pluralidad irreductible de las letras conduce a superar la idea de lo nacional y a pensar más bien en las literaturas colombianas. Podríamos afirmar, insistimos, que el problema sigue siendo el mismo, aunque la amplitud del corpus haya cambiado: ¿en qué términos hablar de las literaturas colombianas? ¿Es posible establecer unas líneas directrices o todo empeño cae en la arbitrariedad del corpus elegido?

Esta pregunta metodológica la ha tenido Álvaro Pineda Botero en sus estudios sobre la producción más contemporánea. Consciente de que los esquemas generacionales, los movimientos y las grandes categorías estéticas carecen de actualidad para adentrarse en el final del siglo xx, Pineda Botero resuelve esta encrucijada a través de una concepción original: «Propongo establecer un eje sincrónico, un abanico, un continuum o campo de transformaciones, limitado por dos polos: el mito y la posmodernidad» (97). En esta visión se trata de responder a un componente sociológico del país, la convivencia de diversos grupos humanos cuyas producciones 
abarcan desde la "visión mítica» de comunidades orales hasta los discursos posmodernos propios de las sociedades urbanas y cosmopolitas. La opción de Pineda Botero, es decir, plantear dos extremos en el vasto conglomerado de textos imaginables, es otra manera de formular, nos parece, ya no desde la fricción política sino desde la realidad sociológica, la tensión entre lo nacional y lo transnacional.

Además de una historiografía que viene redefiniendo los territorios de la literatura colombiana, además de una mirada antropológica sobre las producciones culturales, un tercer elemento que problematiza nuestro tema es la figura del escritor. Si el relato nacional ha cambiado y ya no necesita de la literatura para afirmarse, también se ha modificado la imagen del escritor, es decir, que ya nadie aspira a escribir una novela que defienda el proyecto de la nación colombiana. ¿ $\mathrm{O}$ tal vez sí? Hay una tensión entre la imagen del escritor que todavía está buscando en su obra un correlato de lo nacional, y el escritor que se desprende de dicho compromiso. El escritor puede tener un pie en el mapa del proyecto crítico de la nación, y el otro en el mapa de su geografía personal como novelista. Esa tensión es la que deseamos evidenciar. Pero aclaremos que no se trata de algo propio de nuestro tiempo: «Narradores colombianos, desde Jorge Isaacs hasta García Márquez, han hablado siempre de una literatura latinoamericana o hispanoamericana en lugar de manifestar una concepción colombianista» (Pineda Buitrago 20).

Los escritores luchan por incluirse en un contexto más vasto, a saber, el de la lengua, y es allí donde aspiran a ser leídos. Curiosamente, dicha aspiración, en el caso de Isaacs y de García Márquez, viene acompañada por el deseo de convertirse en el vate nacional. Y esto es así, a tal punto, que la colombianidad puede abordarse haciendo hincapié en la María o en Cien años de soledad. Al alba del siglo XXI, la figura del escritor sigue inmersa en el compromiso democrático, aunque de una manera conflictiva. Ya no se trata de representar algo tan abstracto, desmedido e incluso excluyente como la colombianidad, sino de ponerla en jaque. Es así como Pablo Montoya lo enuncia en su discurso de entrega del Premio Internacional de Novela Rómulo Gallegos:

Vengo de un país llamado Colombia, que es como decir vengo del fuego y el oprobio, del resentimiento y la rabia. Es verdad, por lo demás, que he tenido como uno de mis credos esenciales las palabras de Séneca cuando este le dice a su amigo Lucilio: «Hay que vivir con esta persuasión: no he nacido para un solo rincón, mi patria es todo el mundo visible». Y que la experiencia del exilio que me ha dejado el paso por otras latitudes me hace sentir un hombre de todas partes y de ninguna. Pero, ¿qué sucede cuando ese territorio visible, más o menos inmediato que llamamos patria, está degradado? ¿Podemos sentirnos acogidos por él? ¿Podemos sentirnos vivos y plenos en una patria enferma? (Montoya, Español 75).

Montoya muestra, en las palabras de Séneca, la aspiración y a la vez la utopía de una escritura, ya que escribir siendo colombiano pareciera condenar el escritor a una puesta en escena de la patria degradada. En este contexto, la literatura es un lugar de disidencia imaginativa en el que se confrontan y redefinen los discursos nacionales, un lugar donde la pregunta por la patria se convierte en un angustioso problema narrativo.

\section{¿Hacia una literatura transnacional?}

Las literaturas nacionales están fundamentadas en la noción de territorio o de zonas geográficas. ¿Es posible definir una zona literaria? En el caso de Colombia, cuya vertiente caribe no tiene nada que ver con la literatura urbana y andina, por citar solo dos enclaves, sería interesante pensar en dicha división. Olga Vallejo Murcia, partiendo de la lectura crítica del Atlas, propone tres zonas culturales que permitirían un acercamiento metodológico, teniendo en cuenta tres orígenes: hispanoamericano, amerindio y afrocolombiano (Vallejo Murcia, "Consideraciones» 17-33). Esta fragmentación forma parte de un reconocimiento de las literaturas veladas y subrepticias que han acompañado en silencio la legitimación del canon, división que es fundamental para un estudio historiográfico.

Sin embargo, los historiadores también reconocen la tendencia contraria, es decir, la de pensar el territorio al interior de una dinámica transnacional. Esta aspiración es tan vieja como el afianzamiento de una América Latina, y adquiere todo su esplendor con el modernismo. No hay que esperar a la celebérrima conferencia de Borges, «El escritor argentino y la tradición» (1953), para que el ser nacional se vea como una máscara o un "pseudoproblema». Ya Pedro Henríquez Ureña escribía en 1925, «tenemos derecho a todos los beneficios de la cultura occidental» (53), para reivindicar un espacio donde las naciones 
se desdibujan y los productos culturales no están circunscritos ni condenados a un cerco fronterizo. Y ya a principios de siglo, autores como Max Grillo, Ricardo Tirado Macías y Baldomero Sanín Cano "pretendían insertar la literatura de lengua española, y en especial la colombiana, en la corriente literaria mundial, sin distingos de naciones» (Jiménez 188).

Más de un siglo ha pasado y aún persiste la búsqueda de la identidad local o bien de la pertenencia a los procesos culturales globales. Es por ello que nos interesa resaltar dicha tensión en la manera como se concibe el espacio transnacional actual. En el caso de Colombia, Pablo Montoya afirma que las «tendencias regionalistas» le han dado razón de ser a los discursos literarios anclados en la colombianidad. El escritor se aleja de dicha tradición: «no creo, ni jamás lo he hecho, que la finalidad de un escritor sea la de reflejar en su obra la totalidad de una nacionalidad [...] Pretender en lo que se escribe actos de colombianidad o cosas de esta índole es como entrar en terrenos similares a los que pregonan espectáculos deportivos o populismos políticos» (Montoya, Español 100-101). Montoya va más lejos aún en su crítica, analizando la recepción literaria ya no desde adentro sino desde afuera del espacio nacional:

siempre he pensado, y sobre todo en los tiempos actuales, que el escritor debe escribir no como un exponente nacional sino simplemente como un escritor. Esta suerte de equívoco es lo que, por lo demás, ha llevado a los centros del mundo económico a considerarnos como escritores latinoamericanos, esto es, algo así como criaturas exóticas y partícipes de un gueto, esa tan cacareada latinoamericanidad hecha de patriotismos ridículos y de nostalgias por grandezas que jamás tuvieron lugar, y en donde las poéticas se suceden unas a otras. Primero fue el realismo telúrico, luego el realismo indigenista, después el realismo maravilloso, más tarde el realismo mágico y ahora los diversos realismos sucios y criminales [...] Se ha etiquetado a los escritores colombianos porque escriben sobre un tema recurrente que, según algunos, es propiamente colombiano (101-102).

Lo nacional no solo se construye a partir de la perpetuación de los libros y las lecturas que surgen del espacio republicano, sino también, y en gran medida, a partir de la tensión que se establece con la literatura mundial; y dicho diálogo está dado, en parte, por las leyes del mercado que estigmatizan los productos culturales. Los escritores se encuentran pues entre una fuerza nacional que legitima su producción y su interpretación en el campo de la crítica, y una fuerza mundial, económica y reductora que los potencia o los aplasta y frente a la cual luchan desde la escritura para reivindicar su pertenencia a un espacio sin fronteras, lejos del exotismo, el folclor y otras taras que forman parte del imaginario cuando se piensa en Colombia.

Montoya hace evidente dicho combate al señalar «un impulso de ruptura voluntario en la última narrativa», "que tiene que ver con la demolición de lo nacional» (104). Montoya identifica una tradición de la desnacionalización, en la cual él se incluye junto a escritores anteriores como Darío Ruiz Gómez, Fernando Vallejo, Fernando Cruz Kronfly, R. H. Moreno Durán, Helena Araújo, Marvel Moreno, Albalucía Ángel:

En sus libros hay una lucha por desnacionalizar la literatura realizada desde varios flancos. Desde formas estructurales desvertebradas y fragmentadas, desde la ironía y la diatriba, desde contenidos que muestran una comunidad desarticulada y hastiada de los discursos que el Estado, la Iglesia, los medios de comunicación y la institución militar pregonan sobre una supuesta identidad colombiana (105).

Montoya utiliza el concepto de lo nacional como herramienta para leer la historia de la literatura, ya sea desde una tradición regionalista o desde una franca desnacionalización que busca hacer de la extraterritorialidad el elemento crítico del canon y de su interpretación. Una apuesta extraterritorial es entonces una respuesta a la tradición del realismo nacionalista que se erige desde adentro y sobre todo desde afuera. Y es también una manera de mostrar que el espacio nacional puede aceptar una mirada cosmopolita y global, que la montaña, el valle, la selva y la ciudad son espacios que han perdido sus referentes locales para verse como territorios donde cabe el mundo. Esta lectura condensa la imagen del escritor contemporáneo cuyos derroteros y mecanismos literarios están en el umbral cada vez más amplio de la tensión entre un concepto en crisis como es lo nacional, y un concepto en elaboración, como lo sería lo transnacional.

\section{Montoya y Vásquez: escribir desde la tensión por una literatura sin fronteras}

Como toda obra ambiciosa, Los derrotados no solo es una novela sino también una teoría de la novela. Esta 
se elabora a partir de mecanismos narrativos, aseveraciones directas y conflictos entorno al quehacer del novelista. Uno de esos conflictos paradigmáticos glosa nuestra problemática:

Cuando se escribe de otra cosa que no sea el delito, el robo, la extorsión, el magnicidio, la respectiva masacre, el desaparecido de turno, el escritor termina siendo falso, pedantemente modernista, incapaz de resolver el tema único y escabroso exigido por nuestra historia [...] Claro que se puede escribir sobre otros asuntos, ni más faltaba. Una novela sobre la desnudez y el voyeurismo, cuentos sobre música clásica, diarios de viaje a Europa, ensayos sobre artes plásticas, fotografía y botánica ${ }^{1}$. Pero tarde o temprano te darás cuenta, si eres un escritor colombiano de verdad, de que la realidad que nutre estas circunstancias, digamos íntimas, subjetivas, o extraterritoriales, está urdida por la violencia (145).

En este pasaje hay dos opciones, cuyos extremos pueden representarse por la figura democrática del escritor al servicio de la humanidad, es decir el escritor heredero de la Ilustración, o bien el escritor que sigue el mito romántico del héroe solitario. En Los derrotados, estas facetas se convierten en una sola, si bien predomina la del compromiso con una literatura que expresa los conflictos de la colombianidad. Montoya defiende el derecho que ya pregonaba Henríquez Ureña y Sanín Cano, pero al mismo tiempo es consciente del alcance de la palabra cuando se enfrenta al problema de la literatura nacional. En su discurso de entrega del Premio Iberoamericano de Letras José Donoso, seguramente su texto crítico más desgarrador sobre la necesidad de narrar el país de origen, Montoya define la relación problemática entre la novela y su referente geográfico:

la literatura colombiana ha realizado una labor ejemplar de resistencia que, a mi juicio, ha sido dual. Por un lado, ha dicho ante el olvido que nos puede devorar, que en Colombia sí ha pasado algo y que ese algo es pavoroso, como nos lo recuerda el episodio de Cien años de soledad sobre la masacre de las bananeras. Y, por el otro, que hay una literatura que, al traducirse unas veces en textos de altos valores estéticos, y otras

1. Se trata de un rápido inventario de la obra de Montoya: se alude a La sed del ojo (2004), La sinfónica y otros cuentos musicales (1997), Viajeros (1999), y a múltiples ensayos del autor. en simple y llana denuncia, cuestiona hasta desmontarlo el erróneo orden de cosas que hemos llamado nación colombiana (Montoya, Español 34-35).

La idea de fondo podría glosarse de esta manera: desde la literatura se puede construir un relato frente a un equívoco, frente a una distorsión de la realidad que llamamos Colombia. Los derrotados vuelve sobre la figura del sabio Francisco José de Caldas para contrastar al naturalista con el militar. Dicha figura no es una ínsula sino una clave para comprender la frustración de un proyecto científico, enlodado por el trasfondo bélico de la Independencia. Montoya enlaza ese fracaso con los movimientos revolucionarios de los ańos 70 y las masacres perpetradas por los paramilitares desde finales del siglo xx. En este maremágnum de violencia, el lector debe establecer una continuidad simbólica para tejer una visión de la historia colombiana desde la perspectiva de la guerra y el fracaso. En este sentido, Los derrotados propone una lectura de lo nacional cuyo germen se encuentra en el nacimiento de la soberanía colombiana, pero cuyas estrategias narrativas (la fragmentación, la cronología atomizada, la yuxtaposición de épocas distintas, la mezcla de géneros) forman parte de una novela global, sin otro parentesco nacional distinto, quizá, a La vorágine.

La idea fundamental de Los derrotados, narrar una hipótesis donde cabe la nación colombiana, no está lejos del arte de la conspiración, una de las ideas directrices de La forma de las ruinas, novela que pretende «desmontar» o interrogar el relato más emblemático que ha erigido la sociedad colombiana: la muerte de Jorge Eliécer Gaitán. En la novela de Vásquez se trata de narrar la violencia colombiana pero desde una nueva hipótesis que enlaza la muerte de Gaitán en el 1948 con el asesinato de Uribe Uribe en 1914, y ambos sucesos con el presente del narrador: un manejo de la temporalidad que ya encontramos en Los derrotados, pero sin el ritmo entrecortado que dan los fragmentos. Desentrańar la trama de esas intrigas nacionales que recorren un siglo y que serían como la columna vertebral del país, contribuye a construir uno de los fundamentos de la poética de Vásquez: la certeza de que la historia es una forma literaria.

Vásquez escribe una novela que se quiere nacional y política, sin embargo se apoya en Piglia: retoma la idea de una novela que siga las formas paranoicas de la narración, retoma el mecanismo pigliano de la réplica haciendo del asesinato de Gaitán una réplica del de Uribe Uribe. Se apoya, entre otros, en Cercas 
y su narrativa documentada de los nudos neurálgicos del pasado, su concepción del punto ciego, un mecanismo que define una tradición de novelas en las que «al principio de todas ellas, o en su corazón, hay siempre una pregunta, y toda la novela consiste en una búsqueda de respuesta a esa pregunta central» (17). Y se apoya en lo que podríamos llamar la tradición shakesperiana de la novela. En el ensayo «El espíritu trágico de la novela», incluido en Viajes con un mapa en blanco, Vásquez intenta alejarse del Arte de la novela de Kundera, un libro central en su biografía poética de lector, para formular una idea del género en la que no solo Cervantes traza los ejes que van hasta las grandes invenciones del siglo XIX, sino en la que Shakespeare estaría en el corazón de un tratamiento trágico de la narración. En este ensayo, Vásquez define la matriz de su trabajo como novelista:

La novela que he perseguido desde el principio, o desde lo que yo llamo el principio, es la que pone a prueba una visión de la realidad en que el hombre ha caído en desgracia por culpa de fuerzas que no domina ni entiende, y que le llegan del mundo público o político. Lo que eran los dioses o el destino para los griegos, para mí es la historia (58).

Narrar la caída (una de las líneas de fuerza de Los derrotados), un programa con visos muy concretos y a la vez metafísicos, sería una prolongación de Hamlet, sería reunir en una misma familia Los demonios, Bajo el volcán, ¡Absalón, Absalón!: «Estas novelas (que caprichosamente he querido llamar novelas trágicas) conforman la tradición que me ha rodeado o arropado desde que me preguntaba cómo escribir Los informantes» (59). Recapitulemos lo dicho: la novela política y nacional que es $L a$ forma de las ruinas (cuyo título viene del Julio César de Shakespeare), se hace con materiales colombianos pero al interior de una minuciosa reflexión que quiere establecer puentes con lo transnacional. Y ese diálogo lo hace visible el narrador: «el asesinato de Gaitán [...] es parte de nuestras mitologías nacionales, como puede serlo para un norteamericano el asesinato de Kennedy o el 23 de febrero para un espańol» (25). Uno de los trasfondos de la novela es dicho ejercicio de inducción, en el que la muerte de Gaitán es la manifestación de una geometría planetaria y transhistórica. Es el transfondo, decimos, cuando en la superficie lo que tenemos es la voluntad de escribir una novela míticamente (el neologismo tiene sentido) colombiana. El motor más evidente de la escritura es la línea que borbotea en la superficie. De este modo, relatar la muerte de Gaitán es volver a la hipótesis esgrimida por Gabriel García Márquez en sus memorias, es volver a revisar un siglo de historia bajo la óptica de una trama secreta e impunemente encadenada, es, en palabras de Carlos Carballo, el personaje central, asumir que el autor, Vásquez, en el resto de su obra se ha dejado llevar por la "cobardía» y la falta de "compromiso" y que tiene ante sus ojos la posibilidad de ir al fondo del relato nacional:

Yo leí sus cuentos, los que pasan en Bélgica. Dígame, ¿por qué pierde el tiempo en esas huevonadas? ¿A quién le importan esos personajes europeos que van a cazar en el bosque y se separan de la esposa? Qué frivolidad, por favor, qué tontería. Con una guerra civil aquí en su casa, con más de veinte mil muertos al ańo, con una experiencia de terrorismo como no se ha visto en ningún país de América Latina, con una historia marcada desde el principio por el asesinato de nuestros grandes hombres, y usted escribiendo sobre parejitas que se separan en las Ardenas (154-155).

El pasaje recuerda las lecciones cervantinas, el bachiller Sansón Carrasco hablando con Sancho y don Quijote, en el tercer capítulo de la segunda parte, sobre la lectura de la primera: Cervantes, critica su obra, a través de un diálogo. Vásquez desplaza la escena y se introduce en ella, dejando hablar a Carballo de manera irónica y desenfadada sobre Los amantes de Todos los Santos y Los informantes. Más allá de la técnica, dicha confrontación recuerda el pasaje ya citado de Los derrotados (145): en el interior de la novela está el drama narrativo del escritor colombiano que es leído dentro de un marco que legitima su existencia y su valor, y al mismo tiempo lo encasilla y empobrece. La objeción de Carballo, con la cual intenta persuadir al Vásquez personaje de escribir un libro sobre la teoría conspirativa de dos crímenes, no es solo un juego de artificios. Carballo toca un punto sensible que el autor personaje, en una mirada retrospectiva de su obra, manifiesta sin ambages:

juro que pensé, tras terminar El ruido de las cosas al caer, que así quedaban saldadas mis cuentas personales con la violencia que me había tocado vivir. Ahora me parece increíble no haber comprendido que nuestra violencias no son solamente las que nos tocaron en vida, sino también las otras, las que vienen de antes, porque todas están ligadas (188). 
Dichas «cuentas personales» son las que Vásquez trabaja narrativamente. A partir de un movimiento pendular entre la obsesión por lo nacional y su distancia, entre el compromiso de narrar la violencia y el deseo de escapar a esa tara, se proyecta la novela como una investigación en la que las certezas nacionales se fragilizan. Llevar este conflicto a la narración es poner en evidencia un debate que se agudiza desde la literatura del boom, y que por supuesto ya está en las literaturas del siglo XIx. El narrador de La forma de las ruinas aprovecha esta polémica para mostrar desde un plano autobiográfico dicha ambigüedad:

Nunca me había sentido tan a gusto como en esos años de mi vida en Barcelona, mientras veía crecer a mis hijas y a los hijos de mis amigos y leía libros que nunca había leído y me preguntaba cómo había pasado mi vida sin leerlos [...] Era como si hubiera escapado, sí, me parecía bien ponerlo en esos términos, porque eso hacemos todos los colombianos, en eso se nos va la vida, en tratar de escapar o en preguntarnos por qué no lo hacemos, en llegar a buenos términos con la vida en otra parte o en lidiar con la decisión de no perseguir esa vida. Así sucede que algunos de nosotros vamos poblando Barcelona o Madrid, así hemos hecho de Nueva York la tercera ciudad colombiana del mundo, así acabamos en Miami o en París o en Lima o en Ciudad de México llenando los resquicios como llena el agua los espacios que se le permiten (179).

La condición de «inquilino», término que Vásquez teoriza en su ensayo "Literatura de inquilinos» para referirse a su propia situación en Europa, se expone en este pasaje. Vivir en Barcelona, ocupar esos «resquicios", es decir, llevar una existencia periférica, no es solo una problemática social sino también un dilema narrativo: ¿cómo escribir sobre Colombia, sobre la propia realidad cuando ésta empieza a tomar los visos de lo ajeno, cuando lo conocido se transforma en desconocimiento? La biografía literaria de Vásquez puede llevarnos a una respuesta. El autor ubica su verdadero inicio como novelista con Los informantes, dejando en la prehistoria sus dos primeras novelas. Por supuesto se trata de un juicio estético, y al mismo tiempo de una poética que se consolida a partir de una incógnita, a saber, ¿cómo narrar lo nacional?:

hace un par de años publiqué una novela, Los informantes, que, además de romper con todas las convenciones que hasta entonces había tenido sobre el oficio [...], rompía con varias de mis lealtades literarias más arraigadas y con la mayoría de mis prejuicios, y sobre todo rompía con una de las limitaciones más notorias que hasta entonces había tenido: la imposibilidad de escribir sobre Colombia. Me tomó diez años descubrir el tono adecuado para tocar la realidad desbordante de mi país, una realidad capaz de dejar en ridículo la imaginación más intensa; pero sobre todo me tomó diez años descubrir, gracias a Conrad y Naipaul, que mi país podía ser material novelístico (Vásquez, El arte 179-180).

La poética de Los informantes es fundacional. Detrás de cada novela de Vásquez, detrás de cada obsesión por una zona oscura de la historia nacional, palpita una red de novelas con las que el escritor dialoga y que lo alejan de cualquier indicio de criollismo. En La forma de las ruinas, la extraterritorialidad del escritor entra en juego, es el gran telón de fondo en una novela escrita en Colombia, pero desde las lecciones del exilio voluntario. Tal vez la mayor de ellas sea la conciencia de ser, en primer lugar, un escritor latinoamericano, es decir, un escritor que surge después del boom, después de un fenómeno cultural que borra las fronteras y pregona una «literatura sin pasaporte». Esta afirmación proviene del ensayo "La aplanadora de la historia», un texto pronunciado un mes antes de que saliera La forma de las ruinas, y que podemos leer como la antesala de la novela. Allí, Vásquez se refiere a la «familia» de novelas que lo acompañan. Cita las grandes catedrales del boom, las novelas españolas coetáneas de estas catedrales, como Señas de identidad de Goytisolo, Tiempo de silencio de Luis Martín-Santos, Últimas tardes con Teresa de Juan Marsé; cita El jinete polaco de Antonio Muñoz Molina, Tu rostro mañana de Javier Marías; se extiende en Los soldados de Salamina de Javier Cercas, en Historia argentina de Rodrigo Fresán, en el Borges cuentista. Y en medio de esta familia cruzada de textos que une las dos orillas del Atlántico, Vásquez problematiza la espinosa cuestión que nos ocupa:

A mí, por lo pronto, la idea de «literatura nacional» me provoca poco más que una sonrisa ladeada, irónica y un poco paternalista. Las literaturas nacionales, como bien señaló Borges [...] son un invento de los nacionalismos europeos del siglo XIX, pero hay que decir que sus imitadores latinoamericanos tuvieron mucho éxito: durante la primera mitad del siglo $\mathrm{xx}$, éste fue el mayor esfuerzo de la novela escrita del 
otro lado del océano: hacer país. [...] De las literaturas nacionales pasamos a la literatura latinoamericana; se publicaron entonces las novelas en que mi generación se hundió y se perdió en el afán por encontrarse. El Territorio de la Mancha ensanchado. Pregunta obligatoria: ¿qué hay al final de la línea del tren? ¿Qué viene después, qué hemos heredado nosotros? ¿Estaremos por fin dejando atrás los gentilicios militantes, estaremos ya pensando en la literatura en lengua española como una sola galaxia? (Vásquez, Viajes 121-122).

La pregunta de Vásquez resume el rumbo de su poética y su lectura de la historia literaria colombiana. A un siglo XIX que se debate entre el cosmopolitismo de los modernistas y el regionalismo de los críticos del modernismo, sucede un siglo xx que rompe con los límites de la novela nacional para inscribirse en preocupaciones y sobre en todo en repercusiones continentales. Para Vásquez, el siguiente paso es un diálogo entre América y Europa, una novela cuya frontera estaría en la lengua y no en el territorio. Decíamos que el ensayo «La aplanadora de la historia» era la antesala de La forma de las ruinas. Pues bien, el ensayo acaba con un fragmento de la novela, una extensa cita que viene después de un comentario al final de Cien años de soledad. El ensayo intenta crear vínculos y afinidades para leer la novela como un punto de maduración («en esta novela he puesto todo lo que sé y probablemente sabré en mucho tiempo sobre este género maravilloso»(133), afirma Vásquez); un punto al interior de un mapa donde el lector se vea propulsado a una narrativa global.

\section{Conclusión}

Con este artículo, vemos que la noción de literatura nacional se ha resquebrajado por la presencia de un imperativo continental, por la reivindicación de literaturas marginadas que no hicieron parte de la novela nacional cuando la cultura estaba subordinada a la política y la identidad, y en tercer lugar por la voluntad de los escritores de ser leídos fuera de su contexto de producción y en relación con una geografía más vasta, a saber, la de la literatura como fenómeno mundial.

Los derrotados y La forma de las ruinas hacen explícito el conflicto entre una realidad tremebunda que exige al escritor desarrollar una temática, tomar posición, traducir para los otros la hecatombe de la historia nacional, y una conciencia libre de cualquier dependencia, libre de cualquier sometimiento a valores que no sean estéticos o que se relacionen con una estética subjetiva e independiente. Ambas novelas podrían leerse bajo el prisma del compromiso imaginativo por narrar lo nacional; ambas elaboran una mirada indignante de la historia colombiana y señalan los responsables visibles e invisibles que han logrado salir indemnes; las dos novelas construyen espacios textuales complejos, y establecen una tensión entre la literatura colombiana y la literatura mundial, inscribiéndose en esta última, o mejor, llevando las temáticas vernáculas a modos de expresión extraterritoriales. Las novelas que hemos tratado interrogan el vínculo entre arte y política, e intentan desnacionalizar su origen, construyendo una autonomía que les permita ser vistas no como productos culturales colombianos sino como novelas de un nuevo espacio en formación. Sin ser novelas modernistas, su combate no difiere del que tuvieron a finales del siglo XIX algunos escritores por sacar las letras de los estigmas nacionales y así ser modernos, es decir, no ser nacionales. Nuestra literatura parece construirse bajo dicha dualidad.

\section{Bibliografía}

Cercas, Javier. El punto ciego, Barcelona: Random House, 2016.

Henríquez Ureña, Pedro. La utopia de América, Angel Rama y Rafael Gutiérrez Girardot (compiladores), Caracas: Fundación Biblioteca Ayacucho, 1978.

JimÉnez, David. Historia de la crítica literaria en Colombia 1850-1950, Bogotá: Universidad Nacional de Colombia, 2009.

Montoya, Pablo. Español, lengua mía y otros discursos, Medellín: Sílaba, 2017.

Montoya, Pablo. Los derrotados, Medellín: Sílaba, 2012.

Pineda Botero, Álvaro. «Del mito a la posmodernidad: la novela colombiana de finales de siglo xx", Luz Mery Giraldo B. (coordinación y compilación), La novela colombiana ante la critica 1975-1990, Cali: Editorial Facultad de Humanidades, Centro editorial javeriano Ceja, 1994, pp. 97-112.

Pineda Buitrago, Sebastián. Breve historia de la narrativa colombiana. Siglos XVI-XX, Bogotá: Siglo del Hombre Editores, 2012.

Toro, Diana Carolina. "Historias literarias nacionales: una realidad política», Lingüistica y literatura, No. 49, (2006), pp. 51-73. 
Vallejo Murcia, Olga. "Colombia: tradiciones de la palabra. Balance y proyecciones», Olga Vallejo Murcia, Alfredo Laverde Ospina (coordinadores), Visión histórica de la literatura colombiana. Elementos para la discusión. Cuadernos de trabajo I, Medellín: La carreta editores, 2009, pp. 15-42.

Vallejo Murcia, Olga. «Consideraciones para la definición de la zona literaria colombiana», Olga Vallejo Murcia, Alfredo Laverde Ospina (coordinadores), Tradiciones y configuraciones discursivas: historia critica de la literatura colombiana. Elementos de discusión. Cuadernos de trabajo II, Medellín: La carreta editores, 2010, pp. 17-33.

VÁsQuez, Juan Gabriel. El arte de la distorsión, Bogotá: Alfaguara, 2009.

VÁsQUEZ, Juan Gabriel. La forma de las ruinas, Barcelona: Alfaguara, 2016.

VÁsquez, Juan Gabriel. Viajes con un mapa en blanco, Barcelona: Alfaguara, 2018. 